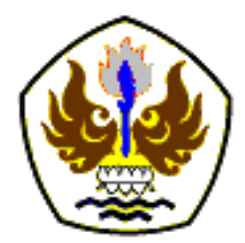

INFOMATEK

Volume 22 Nomor 1 Juni 2020

\title{
AUDIT SISTEM INFORMASI INVENTORY PADA PT. KARINA MENGGUNAKAN FRAMEWORK COBIT 5
}

\author{
Maulana Malik Ibrahim, Ridzwan Delian Kautsar, Salsa Fashihatul Muwahid, \\ Siti Rohmah*), Tantan Nur IIman \\ Program Studi Sistem Informasi \\ Universitas ARS
}

\begin{abstract}
Abstrak: PT. Kaldu Sari Nabati (Karina) merupakan perusahaan yang bergerak dalam bidang makanan ringan yang telah mengimplementasikan Sistem Informasi pada bagian Inventory. Permasalahan yang sering terjadi adalah tidak sesuainya data yang dihasilkan oleh Sistem Informasi yang digunakan. Untuk memastikan bahwa prosedur yang digunakan perusahaan berjalan dengan semestinya, maka perlu dilakukan Audit Sistem Informasi. Audit dilakukan dengan menggunakan Framework COBIT 5 yang merupakan standar COBIT versi terbaru yang dipublikasikan oleh Information System Audit and Control Association (ISACA). Penelitian ini akan berfokus pada domain Monitor, Evaluate and Assess (MEA) dengan sub-domain MEA02. Dalam pengumpulan data dan informasi, peneliti melakukan observasi, wawancara dengan staf kepegawaian IT PT.Karina dan menggunakan kuesioner dengan metode skala likert. Berdasarkan penelitian ini, ditemukan bahwa sub-domain MEA02 menghasilkan indeks 3 . Kesimpulannya adalah nilai capability berada pada level ke 3 atau nilai Established Process yang menunjukkan bahwa perusahaan sudah mengimplementasikan proses yang sudah ditetapkan oleh Sistem Operasional Prosedur.
\end{abstract}

Kata kunci: Audit Sistem Informasi, COBIT 5, MEA

\section{PENDAHULUAN}

Saat ini Sistem Informasi merupakan syarat mutlak untuk kemajuan sebuah perusahaan. Sistem informasi yang mengelola data produksi harus memberikan informasi yang sesuai dengan pergerakan barang yang berlangsung, keamanan data, keefektifan, keefisienan, kerahasiaan data, dan ketersediaan data harus dapat di kontrol dengan baik (Anderson dkk. [1]).

*) sitirohmah040198@gmail.com

Pertama diterima: 8 Mei 2020

Direvisi: 18 Mei 2020

Disetujui untuk publikasi: 29 Mei 2020
Salah satu pemanfaat Sistem Informasi pada suatu perusahaan yaitu dengan adanya Sistem Informasi Persediaan (Inventory). Setiap perusahaan, apakah perusahaan itu perusahaan perdagangan ataupun perusahaan pabrik serta perusahaan jasa selalu mengadakan persediaan. Tanpa adanya persediaan, para pengusaha akan dihadapkan pada resiko bahwa perusahaannya pada suatu waktu tidak dapat memenuhi keinginan pelanggan yang memerlukan atau meminta barang/ jasa. Persediaan diadakan apabila keuntungan 
yang diharapkan dari persediaan tersebut hendaknya lebih besar dari pada biaya-biaya yang ditimbulkannya (Nugrahanti [2]).

PT. Kaldu Sari Nabati (Karina) merupakan perusahaan yang bergerak dalam bidang makanan ringan yang telah mengimplementasikan Sistem Informasi pada bagian Inventory dengan tujuann untuk mengontrol produk dari perusahaan. Permasalahan yang sering terjadi adalah tidak sesuainya data yang dihasilkan oleh Sistem Informasi yang digunakan. Oleh karena itu harus ada langkah-langkah atau tindakan yang dilakukan agar permasalahan yang terjadi dapat teratasi dengan baik dan cepat.

Berdasarkan permasalahan yang ada di PT Karina maka salah satu upaya untuk mengatasi permasalahan tersebut adalah dengan melakukan Audit Sistem Informasi Inventory Pada PT. Karina, adapun Framework yang digunakan dalam penelitian ini menggunakan framework COBIT 5.

Audit sistem informasi berfungsi untuk memastikan sistem informasi dalam perusahaan ini melakukan pengamanan aset informasi, menggunakan sistem dengan efektif dan efisien dan menjaga integritas (Elshaddai dkk. [3]). Audit sistem dapat dilakukan dengan Metode Cobit 5 (Jumalianto dkk. [4])
Audit Sistem Informasi dilakukan untuk memastikan bahwa di perusahaan prosedur yang digunakan berjalan dengan semestinya. Maka dari itu penulis menggunakan COBIT 5 sebagai kerangka kerja yang digunakan dalam mengaudit sistem informasinya. Cobit merupakan sebuah kerangka menyeluruh yang dapat membantu perusahaan dalam mencapai tujuannya (Sulaeman [5]).

\section{METODOLOGI}

\subsection{Diagram Alur Penelitian}

Gambar 1 memperlihatkan diagram alur dalam metodologi penelitian yang dilakukan.

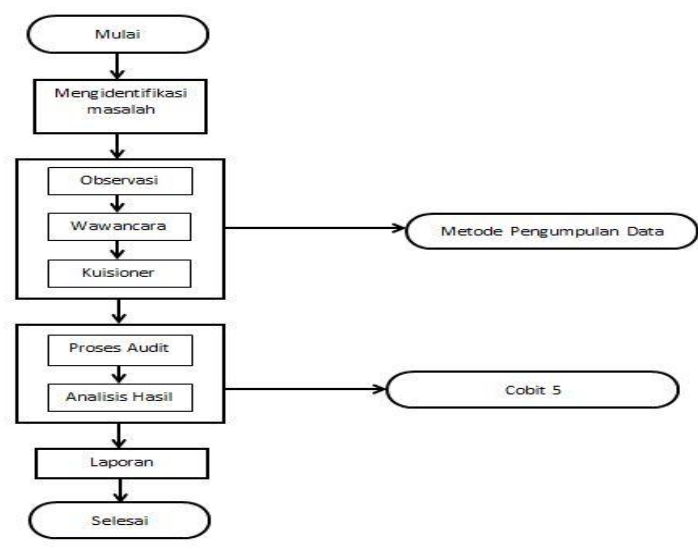

Gambar 1

Diagram Tahapan Penelitian

\subsection{Tahapan-Tahapan Diagram Alur Metode} Penelitian

Adapun tahapan-tahapannya adalah sebagai berikut:

1. Identifikasi Masalah

Penelitian diawali dengan melakukan analisis dan identifikasi suatu masalah yang terjadi 
pada PT. Karina, dan bagaimana cara memecahkan permasalahannya.

\section{Metode Pengumpulan Data}

Pada tahapan kedua yaitu metode pengumpulan data yang dilakukan dengan cara:

\section{a. Observasi}

Pada penelitian ini, akan menganalis alur dari sistem informasi inventory PT. Karina

b. Wawancara

Wawancara dilakukan dengan staf kepegawaian IT PT.Karina

c. Kuisioner .

Dalam penelitian ini menggnnakan kuesioner dengan metode skala likert. Pertanyaan yang diajukan dalam kuesioner berdasarkan pada framework.

\section{ANALISIS DAN PEMBAHASAN}

\subsection{Proses Audit}

Audit sistem informasi inventory pada PT. Karina dilakukan menggunakan Framework COBIT 5 dengan subdomain MEA02. Dalam kajian ini menganalisis prosedur yang berhubungan dengan sistem informasi inventory untuk mengetahui kesesuaian terhadap sistem operasional prosedur yang diterapkan dengan cara menyebarkan kuesioner kepada staf pegawai yang ada di lingkungan IT PT. Karina. Dari penyebaran kuesioner didapatkan hasil sebagaimana terlihat pada Tabel 1.
Tabel 1.

Perhitungan Kuisioner

\begin{tabular}{|c|c|c|c|c|}
\hline Proses & Jawaban & $\Sigma$ Jawaban & $\Sigma$ Soal & Indeks \\
\hline $\begin{array}{l}\text { MEA02.01 Monitor } \\
\text { internal control }\end{array}$ & 13 & & & \\
\hline $\begin{array}{l}\text { MEA02.02 Review } \\
\text { business process } \\
\text { controls }\end{array}$ & & & & \\
\hline effectiveness & 18 & & & \\
\hline $\begin{array}{l}\text { MEA02.03 } \\
\text { Perform control } \\
\text { self-assessment }\end{array}$ & 18 & & & \\
\hline $\begin{array}{l}\text { MEA02.04 Identify } \\
\text { and report control } \\
\text { deficiencies }\end{array}$ & 14 & 84 & 28 & 3 \\
\hline $\begin{array}{l}\text { MEA02.05 Ensure } \\
\text { that assurance } \\
\text { providers are } \\
\text { independent and } \\
\text { qualified }\end{array}$ & 16 & & & \\
\hline $\begin{array}{l}\text { MEA02.06 Plan } \\
\text { assurance } \\
\text { initiative }\end{array}$ & 5 & & & \\
\hline
\end{tabular}

\subsection{Hasil Audit}

Hasil dari perhitungan kusioner dapat diketahui bahwa nilai capability Audit Sistem Informasi Inventory pada PT. Karina menggunakan Framework COBIT 5 dengan subdomain MEA02 yaitu menghasilkan indeks 3, dan dapat diartikan bahwa nilai capability berada pada level ke 3 atau nilai Established Process yang menunjukkan bahwa perusahaan sudah mengimplementasikan proses yang sudah ditetapkan oleh Sistem Operasional Prosedur. Sistem Operasional Prosedur pada PT. Karina yang berkaitan dengan Sistem Informasi Inventory terdiri dari Prosedur pembelian barang, penerimaan persediaan, dan penggunaan persediaan. 


\section{IV.KESIMPULAN}

Audit Sistem Informasi Inventory pada PT. Karina Menggunakan Framework COBIT 5 dengan hasil pengolahan data nilai capability yaitu indeks 3 . Yang dapat diartikan bahwa nilai capability MEA02 berada pada level 3, proses ini menunjukkan bahwa perusahaan sudah mengimplementasikan proses yang sudah ditetapkan oleh Sistem Operasional Prosedur. Sehingga sudah sesuai dengan Sistem Operasional Prosedur di PT. Karina.

\section{DAFTAR PUSTAKA}

[1] Anderson, R., Kevin, \& Andry, J. F. Audit Aplikasi Inventori Menggunakan Framework Cobit 4.1 Pada Store Nonna. IT Journal Research and Development, 1, 2018.
[2] Nugrahanti, F. Perancangan Sistem Informasi Inventory Menggunakan Visual Delphi 7. SENTIKA, hal. 364, 2015.

[3] Elshaddai, S. B., \& Andry, J. F. (2018). Audit Sistem Informasi Inventori Menggunakan Kerangka Kerja Cobit $5 \mathrm{Di}$ PT. Everlight. Ikraith

[4] Jumalianto, M. F., \& Andarsyah, R. Audit Sistem Informasi Rise (Radio Integrated Broadcasting System) Web Pada PT. Zamrud Khatulistiwa Technology Dengan Menggunakan Metode Cobit 5 . Teknik Informatika, pp. 39-46, 2019.

[5] Sulaeman , F. S. Audit Sistem Informasi Framework Cobit 5. Media Jurnal Informatika , 37, 2015. 